\title{
Ultrasound-Assisted Extraction and Biological Activities of Extracts of Brassica oleracea var. capitata
}

\author{
Valéria Dal Prá ${ }^{1}$, Carolina Bolssoni Dolwitsch ${ }^{1}$, Fernanda Oliveira Lima², \\ Camilo Amaro de Carvalho ${ }^{3}$, Carine Viana ${ }^{1}$, Paulo Cícero do Nascimento ${ }^{4}$ and \\ Marcelo Barcellos da Rosa ${ }^{1,4 *}$ \\ ${ }^{1}$ Post-Graduate Program in Pharmaceutical Sciences, Federal University of Santa Maria, \\ Camobi Campus, 97105-900 Santa Maria, RS, Brazil \\ ${ }^{2}$ Federal University of Fronteira Sul, Centro, 97900-000 Cerro Largo, RS, Brazil \\ ${ }^{3}$ Medical and Nursing Department, Federal University of Viçosa, Av. Peter Henry Rolfs, s/n, \\ 36570-000 Viçosa, Brazil \\ ${ }^{4}$ Post-Graduate Program in Chemistry, Federal University of Santa Maria, Camobi Campus, \\ 97105-900 Santa Maria, RS, Brazil \\ Received: October 4, 2013 \\ Accepted: January 26, 2015
}

\begin{abstract}
Summary
In this work, the antioxidant and antimicrobial activities of Brassica oleracea var. capitata extracts obtained through ultrasound-assisted extraction are evaluated. The extracts obtained using the best extraction conditions were subjected to different hydrolysis conditions before their use in the biological tests. The crude and hydrolysed extracts were characterized using gas chromatography coupled with a mass detector. The use of ultrasound at 30 ${ }^{\circ} \mathrm{C}$ with $60 \%$ (by volume) solvent enabled obtaining a richer extract. All extracts had antioxidant activities against DPPH (13.0-80.0\%), superoxide (35.2-63.2 \%) and peroxyl (89.3$99.5 \%$ ) radicals, but the use of hydrolysed extracts considerably improved the antioxidant activities. Antimicrobial activities only of the hydrolysed extracts of Brassica oleracea var. capitata were detected. It was confirmed that antioxidant activity of vegetable extracts can be considerably increased when hydrolysis is applied as a pretreatment to their extraction.
\end{abstract}

Key words: Brassica oleracea var. capitata, ultrasound-assisted extraction, hydrolysis of extracts, biological activity

\section{Introduction}

Brassica sp. is a vegetable belonging to the family Brassicaceae, which is one of the most important families cultivated worldwide. Some species of this family are of pharmacological interest. Several studies have revealed that they exhibit anti-inflammatory, antimycotic, photoprotective, antihyperglycemic, anticarcinogenic and antioxidant activities (1-3). Among the various Brassica species, Brassica oleracea L. var. capitata (cabbage) has been widely studied because of its biological activities (4).
Several authors have reported antioxidant activities of extracts of Brassica against different radicals. Among the methods for testing the ability of some compounds to act as free radical scavengers is the 1,1-diphenyl-2-picrylhydrazyl (DPPH) assay. This procedure has been widely used to evaluate the antiradical activity of several plants, including extracts of Brassica sp., because it is considered to be an easy, precise and reproductive test for evaluating the antioxidant activity (5-7). The antioxidant potential of Brassica extracts against superoxide radicals $\left(\mathrm{O}_{2}{ }^{--}\right)$, which can cause indirect damage because they lead to the for- 
mation of hydroperoxides through the autoxidation of unsaturated fatty acids, was also investigated $(5,8,9)$. However, the use of Brassica extracts against the peroxyl radical (ROO'), which is an important intermediary in lipid peroxidation, has not been considered much. Specifically, Zhou and $\mathrm{Yu}(10)$ evaluated the scavenging activities of vegetables, including broccoli and kale, against DPPH, $\mathrm{ROO}^{\circ}$ and $\mathrm{O}_{2}{ }^{\circ}$, whereas $\mathrm{Ou}$ et al. (11) determined the antioxidant activity of white cabbage and broccoli extracts against peroxyl radicals.

Extracts of Brassica are also used as antimicrobial agents. The antibacterial activity of ethanol, methanol and acetone extracts obtained from Brassica oleracea was investigated against Salmonella Abony, Pseudomonas aeruginosa, Listeria monocytogenes and Enterococcus faecalis (12). Blazevic et al. (13) tested the antibacterial activity of aqueous extracts of Aurinia sinuata (L.) Griseb. (a genus of flowering plant from Brassicaceae family) against Staphylococcus aureus, Bacillus cereus, Clostridium perfrigens, Enterococcus faecalis, Micrococcus luteus, Aeromonas hydrophila, Chryseobacterium indologenes, Enterobacter sakazakii, Enterobacter cloacae, Escherichia coli, Klebsiella pneumoniae, Pseudomonas aeruginosa, Pseudomonas luteola and Vibrio vulnificus.

However, the biological activity of extracts obtained from plant species is related to the extraction method because each method affects the selectivity of the compounds. In this way, novel extraction techniques, such as the ultrasound-assisted method, have been used to obtain plant extracts. The use of ultrasound can increase cell wall destruction, cause leakage of cellular material, enhance the penetration of solvent into plant cells, facilitate hydration and swelling, and improve mass transfer. These phenomena can increase the extraction of antioxidants while significantly reducing the extraction time, thus improving overall efficiency. Ultrasound-assisted extraction (UAE) is versatile and can be performed on small and large scale (14-16). Li et al. (17) evaluated ultrasound-assisted extraction of carotenoids, Pingret et al. (18) investigated ultrasound-assisted water extraction of polyphenols from apple pomace, while Achat et al. (19) evaluated the enrichment of olive oil with oleuropein by ultrasound-assisted maceration.

Therefore, the objective of this study is to evaluate the antioxidant and antimicrobial activities of Brassica oleracea var. capitata (white cabbage) extracts obtained using ultrasound-assisted extraction. First, the extraction conditions were optimized, and then the extracts were submitted to different hydrolysis conditions before their use in the biological evaluations. The crude and hydrolysed extracts were characterized using gas chromatography coupled with mass spectrometry (GC-MS).

\section{Materials and Methods}

\section{Chemicals}

Sodium hydroxide, 4-(2-hydroxyethyl)-1-piperazineethanesulphonic acid (HEPES), 2,2'-azobis(2-aminodinopropane hydrochloride) (ABAP), 2',7'-dichlorofluorescin (DCFH2-DA), xanthine oxidase (XOD) 25 UN, hypoxanthine (HPX), nitrotetrazolium blue chloride (NBT) and 1,1-diphenyl-2-picrylhydrazyl (DPPH) were obtained from
Sigma-Aldrich, St. Louis, MO, USA. Dimethyl sulphoxide (DMSO), potassium chloride and magnesium chloride were obtained from Isofar ${ }^{\circledR}$ (Rio de Janeiro, Brazil). Sodium carbonate was obtained from Merck (Darmstadt, Germany). Ethylenediaminetetraacetic acid (EDTA) was obtained from Nuclear ${ }^{\circledR}$ (Diadema, Brazil). Ultrapure water was obtained from a Milli-Q system UV Synergy ${ }^{\circledR}$ (Millipore SA, Molsheim, France). The solvents methanol, acetonitrile and anhydrous ethanol, all of HPLC grade, were obtained from the Tedia Company (Fairfield, OH, USA). The microorganisms used in the tests (Staphylococcus aureus ATCC 29213 and Escherichia coli ATCC 14948) were obtained from the Laboratory of Immunobiology and Molecular Glycobiology, Federal University of Viçosa, Viçosa, Brazil.

\section{Samples}

Brassica oleracea var. capitata (white cabbage) was bought in a local supermarket in Santa Maria, Rio Grande do Sul, Brazil, in January 2011. The sample was dried in an oven with air circulation at $60^{\circ} \mathrm{C}$ for $72 \mathrm{~h}$, according to Tanongkankit et al. (20). Next, the material was ground and stored at room temperature under a nitrogen atmosphere prior to extraction.

\section{Ultrasound-assisted extraction}

Experiments were performed in a reactor with a thermostatic water bath (temperature accuracy of $\pm 1.0^{\circ} \mathrm{C}$ ). The experimental setup consisted of an ultrasonic bath (model USC 1800A, Unique Inc., Indaiatuba, SP, Brazil) equipped with a transducer with longitudinal vibrations. The ultrasonic unit had an operating frequency of $40 \mathrm{kHz}$ and a maximum ultrasound power output of $132 \mathrm{~W}$. The ultrasonic transducer (surface area of $282.2 \mathrm{~cm}^{2}$ ) was fitted at the bottom of the bath horizontally along the length of the bath, corresponding to an ultrasonic intensity of 0.46 $\mathrm{W} / \mathrm{cm}^{2}$.

For the optimization of the extraction conditions, a central composite rotational design (CCRD) with two independent variables was constructed to evaluate the influence of ethanol fraction and temperature on the extraction (21). Table 1 presents the investigated range for each independent variable. The extractions were performed in the ultrasonic bath for 120 min using an Erlenmeyer flask containing $2 \mathrm{~g}$ of dry material and $10 \mathrm{~mL}$ of an aqueous solution of ethanol. The same experiment was performed in duplicate in the presence and absence of ultrasound irradiation for comparison. In this paper, the evaluated response was the sum of the area of all compounds identified by HPLC. For comparison, an extraction was performed by substituting ethanol with methanol under the optimized experimental conditions because there is a difference in the polarity of these two solvents.

\section{Hydrolysis of the crude extracts}

The hydrolysis of the crude extracts (methanolic and ethanolic) obtained using the best experimental conditions of the previous step was performed following the method proposed by Robbins et al. (22) with some modifications. Acid hydrolysis consisted of treating $2 \mathrm{~mL}$ of the crude extract with $1 \mathrm{~mL}$ of $\mathrm{HCl}(2 \mathrm{M})$ and then heating the 
Table 1. Experimental conditions used to compare HPLC peak areas after $120 \mathrm{~min}$ in the presence and absence of ultrasound

\begin{tabular}{|c|c|c|c|c|c|}
\hline \multirow[t]{2}{*}{ Run } & \multirow{2}{*}{$\begin{array}{c}\begin{array}{c}\text { Tempera- } \\
\text { ture }\end{array} \\
{ }^{\circ} \mathrm{C}\end{array}$} & \multirow{2}{*}{$\frac{\varphi(\text { ethanol })}{\%}$} & \multirow{2}{*}{$\frac{\text { Peak area }}{\mathrm{mAU}}$} & \multirow{2}{*}{$\begin{array}{c}\begin{array}{c}\text { Peak } \\
\text { area }_{\mathrm{US}}\end{array} \\
\mathrm{mAU}\end{array}$} & \multirow{2}{*}{$\begin{array}{c}\begin{array}{c}\text { Peak area } \\
\text { increase }\end{array} \\
\%\end{array}$} \\
\hline & & & & & \\
\hline 1 & 36 & 32 & 107.75 & 177.81 & 39.4 \\
\hline 2 & 64 & 32 & 105.90 & 198.99 & 48.8 \\
\hline 3 & 36 & 88 & 73.81 & 174.51 & 57.7 \\
\hline 4 & 64 & 88 & 67.57 & 158.17 & 57.3 \\
\hline 5 & 30 & 60 & 237.90 & 494.25 & 51.9 \\
\hline 6 & 70 & 60 & 186.87 & 231.89 & 19.4 \\
\hline 7 & 50 & 20 & 74.62 & 118.87 & 37.2 \\
\hline 8 & 50 & 100 & 35.44 & 46.71 & 24.1 \\
\hline 9 & 50 & 60 & 126.86 & 167.33 & 24.2 \\
\hline 10 & 50 & 60 & 142.43 & 184.39 & 22.8 \\
\hline 11 & 50 & 60 & 137.44 & 164.59 & 16.5 \\
\hline
\end{tabular}

Peak area increase $=100-\left(\frac{\text { Peak area }}{{\text { Peak } \text { area }_{\mathrm{US}}}}\right) \cdot 100$

US=ultrasound, AU=arbitrary units

mixture to $95{ }^{\circ} \mathrm{C}$ for $1.5 \mathrm{~h}$. Alkaline hydrolysis consisted of treating $5 \mathrm{~mL}$ of the extract with $5 \mathrm{~mL}$ of an alkaline solution (2 M NaOH, $10 \mathrm{mM}$ EDTA and $1 \%$ ascorbic acid). The reaction mixture was maintained at $30{ }^{\circ} \mathrm{C}$ under stirring for $30 \mathrm{~min}$. Next, the $\mathrm{pH}$ was adjusted to 3.0 with $8 \mathrm{M} \mathrm{HCl}$ solution, and extraction with ethyl acetate (two 5-mL portions) using sonication for $20 \mathrm{~min}$ was performed. Organic solvent was removed using a rotary evaporator. The solid residue was resuspended in $2 \mathrm{~mL}$ of methanol and filtered (polyvinylidene fluoride, particle size $0.22 \mu \mathrm{m})$. Prior to testing for antioxidant and antibacterial activities, these extracts were neutralized.

\section{Chromatographic analysis}

In the extraction step, high-performance liquid chromatography (HPLC) was employed to separate the compounds according to the method proposed by Leoni et al. (23) with some modifications. For this purpose, a Dionex HPLC (model P680, UV-VIS detector UVD-170 Dionex $\mathrm{GmbH}$, Germering, Germany) equipped with a column ODS-18 (250 mm $\times 5 \mu \mathrm{m}$, Thermo Scientific, Waltham, MA, USA) using a $\mathrm{CH}_{3} \mathrm{CN} / \mathrm{H}_{2} \mathrm{O}$ 15:85 mixture as the eluent was used. A flow rate of $1.0 \mathrm{~mL} / \mathrm{min}$, wavelengths of 240 and $254 \mathrm{~nm}$ and a total run time of $15 \mathrm{~min}$ were employed.

The identification of compounds present in the crude and hydrolysed extracts was performed only in the optimized run of the experimental design (methanolic and ethanolic extracts) using gas chromatography coupled with mass spectrometry detector (GC-MS). The extracts were analyzed with a gas chromatograph (HP 6890, Agilent, Ramsey, MN, USA) interfaced with a mass selective detector (HP 5973, Agilent) with an automatic injection system (HP 6890, Agilent), using a capillary column HP$-5 \mathrm{~ms}(30 \mathrm{~m} \times 0.32 \mathrm{~mm} \times 0.25 \mu \mathrm{m})$. Helium was the carrier gas with a flow rate of $2 \mathrm{~mL} / \mathrm{min}$ at a pressure of 0.35 bar and electronic impact mode of $70 \mathrm{eV}$. Samples of $1 \mu \mathrm{L}$ were injected at $250{ }^{\circ} \mathrm{C}$ interface temperature with the fol- lowing column temperature gradient programming: 70 ${ }^{\circ} \mathrm{C}$ for $1 \mathrm{~min}$, then $12{ }^{\circ} \mathrm{C} / \mathrm{min}$ up to $280^{\circ} \mathrm{C}$.

\section{Antioxidant activities of extracts}

\section{Radical DPPH scavenging activity}

The analytical method by Zhao et al. (24), with modifications, used to measure the radical scavenging activity of crude and hydrolysed extracts of Brassica oleracea var. capitata against DPPH radical was based on the addition of $1500 \mu \mathrm{L}$ of extract to $1480 \mu \mathrm{L}$ of DPPH solution plus 20 $\mu \mathrm{L}$ of hydroethanolic solution. A blank assay was performed using $1500 \mu \mathrm{L}$ of hydroethanolic solution instead of the extract. The resulting solution was left to rest for 30 min. Then, the absorbance of samples was determined at $522 \mathrm{~nm}$ using UV-VIS 8453 Hewlett-Packard spectrophotometer (Agilent Technologies, Santa Clara, CA, USA). The antiradical activity against $\mathrm{DPPH}\left(\mathrm{AA}_{\mathrm{DPPH}}\right)$ was calculated according to the following equation:

$$
\mathrm{AA}_{\mathrm{DPPH}}=\left(\frac{A_{\mathrm{DPPH}}-\left(A-A_{\mathrm{B}}\right)}{A_{\mathrm{DPPH}}}\right) \cdot 100
$$

where $A_{\mathrm{DPPH}}, A$ and $A_{\mathrm{B}}$ are the absorbance of the DPPH solution, sample and blank, respectively.

\section{Superoxide anion radical scavenging activity}

The antiradical activity of Brassica oleracea var. capitata extracts, obtained by ultrasound-assisted extraction, against $\mathrm{O}_{2}{ }^{-}$- radicals was evaluated by the enzymatic system HPX/XOD (24). For this purpose, $100 \mu \mathrm{L}$ of EDTA (30 $\mathrm{mmol} / \mathrm{L}), 100 \mu \mathrm{L}$ of $\mathrm{HPX}(3 \mathrm{mmol} / \mathrm{L})$ and $200 \mu \mathrm{L}$ of NBT $(1.42 \mathrm{mmol} / \mathrm{L})$ were mixed with $100 \mu \mathrm{L}$ of extract. After 3 min, $100 \mu \mathrm{L}$ of enzyme XOD $(0.75 \mathrm{U} / \mathrm{mL}$, diluted in phosphate buffer) were added. The final volume of the solution was brought to $3 \mathrm{~mL}$ with phosphate buffer $(0.05$ $\mathrm{mol} / \mathrm{L}, \mathrm{pH}=7.4)$. The blank sample was prepared in the same manner but without the NBT. Additionally, a control test was performed containing all reagents with the solvent employed in the samples and a blank control. After $40 \mathrm{~min}$ of reaction, the absorbance of the samples was measured using UV-VIS 8453 Hewlett-Packard spectrophotometer (Agilent Technologies) at $560 \mathrm{~nm}$. The antiradical activity against $\mathrm{O}_{2}{ }^{-}{ }^{-}\left(\mathrm{AA}_{\left.\mathrm{O}_{2}-{ }^{-}\right)}\right.$was calculated according to the following equation:

$$
\mathrm{AA}_{\mathrm{O}_{2}^{--}}=\left(1-\frac{\left(A-A_{\mathrm{B}}\right)}{\left(A_{\mathrm{C}}-A_{\mathrm{BC}}\right)}\right) \cdot 100
$$

where $A$ and $A_{\mathrm{B}}$ are the absorbance of the sample and blank, respectively, and $A_{\mathrm{C}}$ and $A_{\mathrm{BC}}$ are the absorbance of the control and blank control, respectively.

\section{Peroxyl radical anion scavenging activity}

The antiradical activity of Brassica oleracea var. capitata extracts, obtained by ultrasound-assisted extraction, against $\mathrm{ROO}^{\circ}$ radicals was evaluated using the fluorimetric method using DCFH2-DA as a substrate (25). A plate containing 96 wells was subdivided into two regions: the first region corresponded to lines $\mathrm{A}, \mathrm{B}, \mathrm{C}$ and $\mathrm{D}$, and the second region corresponded to lines $\mathrm{E}, \mathrm{F}, \mathrm{G}$ and $\mathrm{H}$. In the first three wells of each region $10 \mu \mathrm{L}$ of solvent were added to the samples. In the remaining wells of the plate, $10 \mu \mathrm{L}$ of the extract were added. Then, $127.5 \mu \mathrm{L}$ of buffer were 
added to all wells of the plate. Subsequently, $7.5 \mu \mathrm{L}$ of ultrapure water were added to all wells of region 1, whereas $7.5 \mu \mathrm{L}$ of $\mathrm{ABAP}(4 \mathrm{mmol} / \mathrm{L})$ were added to the wells of region 2. Before the analysis, $10 \mu \mathrm{L}$ of DCFH2-DA (16 $\mu \mathrm{mol} / \mathrm{L}$ ) were added. A Vitor 2 fluorimeter (PerkinElmer, Waltham, MA, USA) was programmed to maintain the temperature at $37^{\circ} \mathrm{C}$ and to measure the fluorescence at $485 \mathrm{~nm}$ (excitation) and $520 \mathrm{~nm}$ (emission) in regular time intervals of $5 \mathrm{~min}$ for $30 \mathrm{~min}$. The antiradical activity against $\mathrm{ROO}^{\circ}\left(\mathrm{AA}_{\mathrm{ROO}}\right)$ was calculated after $30 \mathrm{~min}$ according to the following equation:

$$
\mathrm{AA}_{\mathrm{ROO}}=\left(1-\frac{\left(F_{\mathrm{A}}-F_{\mathrm{AB}}\right)}{\left(F_{\mathrm{S}}-F_{\mathrm{SB}}\right)}\right) \cdot 100
$$

where $\mathrm{F}_{\mathrm{A}}$ and $\mathrm{F}_{\mathrm{AB}}$ are the fluorescence of the sample containing $\mathrm{ABAP}$ and the fluorescence of the blank without $\mathrm{ABAP}$, respectively, and $\mathrm{F}_{\mathrm{S}}$ and $\mathrm{F}_{\mathrm{SB}}$ are the fluorescence of the solvent containing $\mathrm{ABAP}$ and the fluorescence of the solvent blank without the ABAP, respectively.

\section{Antibacterial activities (S. aureus and E. coli) of extracts}

The antimicrobial activity of crude and hydrolysed extracts of Brassica oleracea var. capitata was determined using the antibiogram with solid-phase (disc-diffusion) methodology. The extracts were resuspended in the extraction solvent (methanol or ethanol) at a concentration of $100 \mathrm{mg} / \mathrm{mL}$. Staphylococcus aureus ATCC 29213 and Escherichia coli ATCC 14948 were inoculated on Müller-Hinton agar and kept in an oven maintained at $(36 \pm 2){ }^{\circ} \mathrm{C}$ for $24 \mathrm{~h}$. As a positive control for $S$. aureus and E. coli, erythromycin $(10 \mu \mathrm{g} / \mu \mathrm{L})$ and ciprofloxacin $(0.1 \mu \mathrm{g} / \mu \mathrm{L})$, respectively, were applied in the same plate. The antimicrobial activity of the solvents (negative control) was also determined. The degree of sensitivity or resistance of a microorganism was determined by measuring the size of the antimicrobial effect zones (size of halo formed). Samples were examined in duplicate against each bacterium.

\section{Statistical analysis}

The statistical analysis was performed using ANOVA coupled with the Tukey's test at a $95 \%$ confidence level using STATISTICA ${ }^{\circledR}$ v. 8.0. (StatSoft Ltd, Tulsa, OK, USA).

\section{Results and Discussion}

\section{Ultrasound-assisted extractions}

The process variables studied in this work were temperature in the range of $30-70{ }^{\circ} \mathrm{C}$ and ethanol volume fraction in the range of $20-100 \%$. All experiments were performed in the presence and absence of ultrasound irradiation. Table 1 presents the results obtained with the CCRD concerning the total HPLC area of all compounds separated in the sample, which ranged from 35.44 to $237.90 \mathrm{mAU}$ and from 46.71 to $494.25 \mathrm{mAU}$ in the absence and presence of ultrasound, respectively. Considering the mean value obtained in the 11th run, significant differences $(p<0.05)$ were detected between the amounts obtained in the absence and presence of ultrasound because the mean values were 137.44 and 164.59 units, respectively.
Fig. 1 presents the extraction profiles in the presence and absence of ultrasound expressed as normalized HPLC peak area. The right y-axis shows the normalized HPLC peak area for both experimental sets, black bars show ultrasound extraction and grey without ultrasound, whereas the left $y$-axis indicates the contribution or increase (white dotted column) in percentage when ultrasound was applied. In all runs, a positive effect of ultrasound in comparison with conventional extraction (maceration) is clearly observed, and an average HPLC peak area increase of $(36.1 \pm 15.5) \%$ was observed.

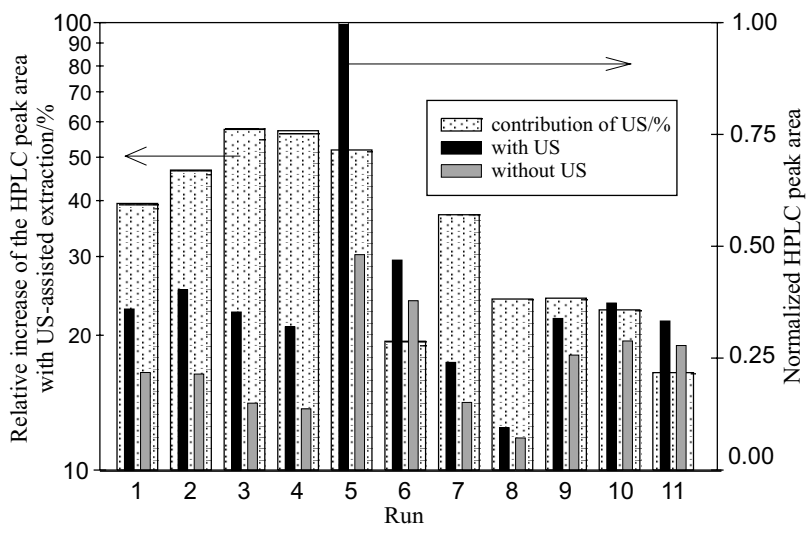

Fig. 1. Comparison between the presence and absence of ultrasound (US) in Brassica extraction after 120 min (right Y-axis) and the contribution/increase of the US (left Y-axis)

Note that the ultrasound effect can be associated with an increase in the mass transfer process during the reaction through the formation of cavitation bubbles, which provide an important benefit of opening up the surface of solid substrates. Consequently, at lower temperatures, the energy provided by the ultrasound is responsible for the improvement in the extraction rates, but at higher temperatures thermal energy is sufficient and the ultrasound exhibits a positive effect on the extraction runs.

Based on the results presented in Table 1, the experimental ultrasound conditions for the extraction of bioactive compounds of Brassica oleracea var. capitata were verified in run $5\left(30{ }^{\circ} \mathrm{C}\right.$ and $60 \%$, by volume, of ethanol) in the presence of the ultrasound. Considering this result, an additional extraction was performed in which ethanol was substituted with methanol, and the obtained peak area of the extracted sample was $330.5 \mathrm{mAU}$. In the following steps, only the crude and hydrolysed extracts obtained using methanol or ethanol were considered.

\section{Gas chromatography-mass spectrometry analysis of Brassica oleracea var. capitata extracts}

The crude and hydrolysed extracts of Brassica oleracea var. capitata obtained by ultrasound-assisted extraction (at $30{ }^{\circ} \mathrm{C}$ and $60 \%$, by volume, of ethanol or methanol) were analyzed with a gas chromatograph interfaced with a mass selective detector. The composition of the extracts obtained in this work was expressed as the percentage of the normalized peak areas, which are presented in Table 2. It was possible to identify 10 compounds, including derivatives of fatty acids, sulphur compounds and glyco- 
Table 2. Chemical profile of crude and hydrolysed extracts of Brassica oleracea var. capitata obtained by ultrasound-assisted extraction

\begin{tabular}{|c|c|c|c|c|c|c|c|c|c|c|c|}
\hline \multirow[b]{2}{*}{ Solvent } & \multirow[b]{2}{*}{ Extract } & \multicolumn{10}{|c|}{$t$ (retention)/min; Normalized peak area/\% } \\
\hline & & $\begin{array}{c}\text { pentanoic } \\
\text { acid }\end{array}$ & $\begin{array}{l}\text { 2-furan- } \\
\text { carbox- } \\
\text { aldehyde }\end{array}$ & L-glucose & phenol & $\begin{array}{c}\text { ethyl } \\
\alpha \text {-D-gluco- } \\
\text { pyranoside }\end{array}$ & $\begin{array}{l}\text { desulpho- } \\
\text { sinigrin }\end{array}$ & $\begin{array}{l}\beta \text {-D-gluco- } \\
\text { pyranose }\end{array}$ & D-manose & $\begin{array}{l}\text { hexa- } \\
\text { decanoic } \\
\text { acid }\end{array}$ & $\begin{array}{l}\text { octa- } \\
\text { decanoic } \\
\text { acid }\end{array}$ \\
\hline \multirow{3}{*}{ Ethanol } & crude & - & - & $7.78 ; 49.00$ & $10.32 ; 9.43$ & - & $11.77 ; 3.00$ & $12.24 ; 1.05$ & $12.41 ; 2.00$ & - & $19.84 ; 11.64$ \\
\hline & $\begin{array}{c}\text { acid } \\
\text { hydro- } \\
\text { lysis }\end{array}$ & $5.15 ; 5.75$ & $7.16 ; 61.10$ & - & - & $11.37 ; 8.52$ & - & - & - & - & - \\
\hline & $\begin{array}{c}\text { alkaline } \\
\text { hydro- } \\
\text { lysis }\end{array}$ & - & - & $11.82 ; 13.00$ & - & - & $10 ; 18.95$ & - & - & $14.45 ; 3.35$ & - \\
\hline \multirow{3}{*}{ Methanol } & crude & - & - & $7.47 ; 0.50$ & - & - & - & - & $12.5 ; 0.75$ & - & \\
\hline & $\begin{array}{l}\text { acid } \\
\text { hydro- } \\
\text { lysis }\end{array}$ & - & $7.16 ; 35.10$ & - & - & $10.9 ; 41.50$ & - & $11.2 ; 2.50$ & - & - & - \\
\hline & $\begin{array}{l}\text { alkaline } \\
\text { hydro- } \\
\text { lysis }\end{array}$ & - & - & - & - & - & - & - & - & $14.45 ; 4.77$ & - \\
\hline
\end{tabular}

sides. The crude ethanol was the sample with the highest number of identified compounds. Desulphosinigrin and octadecanoic acid are among the compounds of interest.

Although flavonoids and glucosynolates, which are usually found in Brassica sp., were not determined in the extracts, a significant amount of glycosides, which are associated with flavonoids and phenolic acids, were found. The presence of these glycosides can indicate the presence of flavonoids in the sample. The hydrolysis of the extracts led to differences in the chemical profiles of the samples. For example, in both acid-hydrolysed extracts, the presence of 2-furancarboxaldehyde, which is a degradation product formed during the acid hydrolysis of glucose, was detected. The degradation of compounds when ultrasound is employed was well reported in the studies of Pingret et al. $(26,27)$, who stated that acoustic cavitation might be responsible for initiating the formation of degradation products, which can trigger radical chain reactions and provoke substantial quality impairments in those products. The use of ultrasound can intensify the hydrolysis of flavonoids, leading to the identification of glycosides in the extract.

In addition, in these same samples, the presence of ethyl $\alpha$-D-glucopyranoside, which is a compound with a positive effect on the prevention of skin barrier disruption (28), was detected. In the crude and alkaline hydrolysis of ethanolic extracts, the presence of desulphosinigrin, a glucosinolate, was observed. Considering the content of fatty acids present in the extracts, hexadecanoic acid was the compound with the highest fraction, 3.35 and $4.77 \%$ in runs 5 and 6, respectively. Fatty acids showed antioxidant (29) and antimicrobial activities (30), which were also evaluated in this study.

\section{Antioxidant activity of ultrasound extracts of Brassica oleracea var. capitata}

Table 3 presents the results concerning the antioxidant activities of the crude and hydrolysed extracts of Brassica oleracea var. capitata obtained using ultrasound-assisted extraction (at $30{ }^{\circ} \mathrm{C}$ and $60 \%$, by volume, of eth-
Table 3. Antioxidant activities of crude and hydrolysed extracts of Brassica oleracea var. capitata obtained by ultrasound-assisted extraction

\begin{tabular}{|c|c|c|c|c|}
\hline \multirow{2}{*}{$\begin{array}{l}\text { Solvent } \\
\text { extraction }\end{array}$} & \multirow{2}{*}{ Extract } & \multicolumn{3}{|c|}{ Antioxidant activity/\% } \\
\hline & & DPPH & $\mathrm{O}_{2}{ }^{\cdot-}$ & $\mathrm{ROO}^{\circ}$ \\
\hline \multirow{3}{*}{ Ethanol } & crude & $(13.0 \pm 0.4)^{\text {ef }}$ & $(35.6 \pm 4.0)^{\mathrm{ef}}$ & $(98.6 \pm 0.1)^{\mathrm{a}}$ \\
\hline & $\begin{array}{c}\text { acid } \\
\text { hydrolysis }\end{array}$ & $(74.0 \pm 3.7)^{\mathrm{abcd}}$ & $(45.3 \pm 2.9)^{\mathrm{d}}$ & $(98.5 \pm 0.3)^{\mathrm{a}}$ \\
\hline & $\begin{array}{c}\text { alkaline } \\
\text { hydrolysis }\end{array}$ & $(70.8 \pm 2.1)^{\mathrm{cd}}$ & $(55.1 \pm 4.1)^{c}$ & $(99.5 \pm 0.1)^{\mathrm{a}}$ \\
\hline \multirow{3}{*}{ Methanol } & crude & $(14.0 \pm 0.6)^{\mathrm{ef}}$ & $(61.1 \pm 5.0)^{\mathrm{ab}}$ & $(97.4 \pm 0.2)^{\mathrm{a}}$ \\
\hline & $\begin{array}{c}\text { acid } \\
\text { hydrolysis }\end{array}$ & $(78.9 \pm 3.1)^{\mathrm{abc}}$ & $(35.2 \pm 3.9)^{\text {ef }}$ & $(97.8 \pm 0.2)^{\mathrm{a}}$ \\
\hline & $\begin{array}{c}\text { alkaline } \\
\text { hydrolysis }\end{array}$ & $(80.0 \pm 4.0)^{\mathrm{abc}}$ & $(63.1 \pm 3.2)^{\mathrm{ab}}$ & $(89.3 \pm 2.8)^{\mathrm{b}}$ \\
\hline
\end{tabular}

$\mathrm{a}, \mathrm{b}, \mathrm{c}, \mathrm{d}, \mathrm{e}, \mathrm{f}$ significant differences at $95 \%(\mathrm{p}<0.05$, Tukey's test $)$

anol or methanol) against $\mathrm{DPPH}, \mathrm{O}_{2}{ }^{-}$and $\mathrm{ROO}{ }^{\circ}$ radicals. All samples showed antioxidant activities, which ranged from 13.0 to $80.0,35.2$ to 63.1 and 89.3 to $99.5 \%$ towards $\mathrm{DPPH}, \mathrm{O}_{2}{ }^{-}{ }^{-}$and $\mathrm{ROO}{ }^{\circ}$ radicals, respectively.

Concerning the antioxidant activity against DPPH radicals, both the methanolic and ethanolic hydrolysed extracts presented higher activities than the crude extracts. These results were statistically evaluated using the Tukey's test $(\mathrm{p}<0.05)$, and the hydrolysed extracts of both methanolic and ethanolic fraction did not present significant differences, even though the hydrolysis process was different.

Against the $\mathrm{O}_{2}{ }^{-}$radical, the crude methanolic extract had a 1.7-fold higher antioxidant activity than the crude ethanolic extract, which was significantly different $(p<0.05)$. This result indicates that the solvent used in the extraction has an influence on the antioxidant activities of the extracts, consistent with the results obtained by Zhao et al. (24), who reported that extracts from a barley variety using $80 \%$ methanol possessed the highest $\mathrm{O}_{2}{ }^{--}$scaveng- 
ing activity, followed by water, $80 \%$ acetone and $80 \%$ ethanol extracts. The hydrolysis of ethanolic extracts had higher activity than the crude extract; however, the acid hydrolysis extracts had a lower activity than alkaline hydrolysis extracts, with the results being statistically significant $(\mathrm{p}<0.05)$. Considering the methanolic extracts, the acid hydrolysis extract had a lower activity than the crude extract, but the alkaline hydrolysis extract had a similar activity as the crude extract, where no significant difference was detected.

The crude and hydrolysed extracts of Brassica oleracea var. capitata obtained by ultrasound-assisted extraction showed the highest antioxidant activity against ROO radicals, which ranged from 89.3 to $99.5 \%$. Only the alkaline hydrolysis of methanolic extract showed a significant difference compared to other extracts. The high inhibitory activity against $\mathrm{ROO}^{\circ}$ radicals verified in all the tested extracts can be attributed to the fact that this radical is less reactive than the other extracts that have been studied (31). Another possibility is related to the high fractions of the extracts $(20 \%)$.

Vrchovská et al. (8) observed the antioxidant activity of aqueous extracts of Brassica oleracea var. costata against DPPH and $\mathrm{O}_{2}{ }^{-}$radicals. The antioxidant activity of Brassica oleracea species (white cabbage and broccoli) obtained using different extraction methods, such as acetone/water 50:50 by volume (11), water extraction in combination with hexane extraction (32) and hexane/dichloromethane (1:1 by volume) in combination with acetone/water/acetic acid (70:29.5:0.5 by volume) (33), also presented activities against ROO' radicals. Podsedek (34) reported that the contribution of Brassica spp. vegetables to better health may be related to their antioxidant capacity.

Although several works have reported the antioxidant activities of extracts from different species of Brassica obtained using different extraction methods $(5,7)$, there is no report on common ultrasound method for obtaining hydrolysed extracts. This paper demonstrates that the hydrolysis process can considerably improve the antioxidant activities of the extracts obtained with ultrasound-assisted extraction. For example, the antioxidant activity against DPPH radicals increased from 13 to $74 \%$ after the acid hydrolysis of the extracts. A similar trend was observed against the $\mathrm{O}_{2}{ }^{\circ}$ - radical, which increased from 35.6 to 55.1 $\%$ after the alkaline hydrolysis of the extracts. In this sense, the main contribution of this work was to demon- strate that the hydrolysis of extracts from vegetable matrices can considerably enhance their antioxidant activity.

\section{Antimicrobial activity of crude and hydrolysed extracts of Brassica oleracea var. capitata}

The antimicrobial activity of the crude and hydrolysed extracts (methanolic and ethanolic) was determined against Gram-positive Staphylococcus aureus and Gram-negative Escherichia coli. Table 4 presents the experimentally determined antimicrobial activities of the extracts obtained in this work. Only the hydrolysed extracts showed antimicrobial activity, where the alkaline hydrolysis extracts showed activity against Escherichia coli, whereas only the acid-hydrolysed methanolic extract had the activity against Staphylococcus aureus. However, the inhibitory halo cannot be considered as a confirmation of antimicrobial activity unless its diameter is $\geq 8 \mathrm{~mm}$ (35).

The results obtained in this study are in good agreement with the literature; Gram-positive bacteria are more resistant than Gram-negative ones because they have thicker cell walls, ranging from $20-80 \mathrm{~nm}$, whereas Gram-negative bacteria have a maximum wall thickness of 20 $\mathrm{nm}$ (36). Other authors have also evaluated the antimicrobial activity of Brassica oleracea extracts. Ayaz et al. (37) evaluated the antimicrobial activity of methanolic extracts of Brassica oleracea L. var. acephala using the same antimicrobial procedure and microorganisms as employed in this work, and verified that the extracts had better activity against $S$. aureus than against $E$. coli.

As verified from the antioxidant activities of the extracts, the hydrolysed extracts of Brassica oleracea var. capitata had higher antimicrobial activities than the crude extracts. This result can be attributed to a difference in the chemical profiles of the samples of the crude and hydrolysed extracts, as shown in Table 2. For example, alkaline hydrolysis enabled the identification of hexadecanoic acid, which shows antimicrobial activity (30), justifying the highest antimicrobial activity of this extract. Another reason for better performance of the hydrolysed extracts is that the extraction procedure used in this work resulted in the extraction of many glycosidic compounds, which have greater activity than the crude extracts after hydrolysis.

Table 4. Antimicrobial activities of crude and hydrolysed extracts of Brassica oleracea var. capitata obtained by ultrasound-assisted extraction

\begin{tabular}{|c|c|c|c|c|c|c|c|c|c|}
\hline \multirow{2}{*}{$\begin{array}{l}\text { Solvent } \\
\text { extraction }\end{array}$} & \multirow{2}{*}{ Extract } & \multicolumn{4}{|c|}{ S. aureus halo/mm } & \multicolumn{4}{|c|}{ E. coli halo/mm } \\
\hline & & $1: 1$ & $1: 2$ & $1: 4$ & $1: 8$ & $1: 1$ & $1: 2$ & $1: 4$ & $1: 8$ \\
\hline \multirow{3}{*}{ Ethanol } & crude & 0.0 & 0.0 & 0.0 & 0.0 & 0.0 & 0.0 & 0.0 & 0.0 \\
\hline & acid hydrolysis & 0.0 & 0.0 & 0.0 & 0.0 & 0.0 & 0.0 & 0.0 & 0.0 \\
\hline & alkaline hydrolysis & 0.0 & 0.0 & 0.0 & 0.0 & $6.3 \pm 0.3$ & 0.0 & 0.0 & 0.0 \\
\hline \multirow{3}{*}{ Methanol } & crude & 0.0 & 0.0 & 0.0 & 0.0 & 0.0 & 0.0 & 0.0 & 0.0 \\
\hline & acid hydrolysis & $4.5 \pm 0.7$ & 0.0 & 0.0 & 0.0 & 0.0 & 0.0 & 0.0 & 0.0 \\
\hline & alkaline hydrolysis & 0.0 & 0.0 & 0.0 & 0.0 & $8.5 \pm 1.4$ & $5.3 \pm 0.3$ & 0.0 & 0.0 \\
\hline No solvent & positive control & 25.0 & nd & nd & nd & 18.0 & 16.0 & nd & nd \\
\hline
\end{tabular}

nd=not determined 


\section{Conclusions}

This work presents important contribution to studying antioxidant activity using a combination of different extraction conditions which allow the identification of different compounds from Brassica oleracea var. capitata. Specifically, the optimization of the ultrasound-assisted extraction of Brassica oleracea var. capitata, the chemical characterization as well as the determination of antioxidant and antimicrobial activities of crude and hydrolysed extracts were successfully done. All extracts showed antioxidant activity against $\mathrm{DPPH}, \mathrm{O}_{2}{ }^{-}$and $\mathrm{ROO}$ radicals; however, the hydrolysed extracts had considerably greater antioxidant activity. Antimicrobial activity was only detected in the hydrolysed extracts of Brassica oleracea var. capitata. Investigation of different ultrasound intensities and the possibility of combining them with other extraction methods is proposed for future investigation.

\section{Acknowledgements}

The authors thank CNPq/Brazil, CAPES and FAPERGS for financial support and scholarships.

\section{References}

1. Kataya HAH, Hamza AA. Red cabbage (Brassica oleracea) ameliorates diabetic nephropathy in rats. Evid Based Compl Altern. Med. 2008;5:281-7.

http://dx.doi.org/10.1093/ecam/nem029

2. Lin JY, Li CY, Wang IF. Characterisation of the pigment components in red cabbage (Brassica oleracea L. var.) juice and their anti-inflammatory effects on LPS-stimulated murine splenocytes. Food Chem. 2008;109:771-81.

http://dx.doi.org/10.1016/j.foodchem.2008.01.039

3. Bajpai VK, Kang SC, Baek KH. Microbial fermentation of cabbage by a bacterial strain of Pectobacterium atrosepticum for the production of bioactive material against Candida species. J Mycol Med. 2012;22:21-9. http://dx.doi.org/10.1016/j.mycmed.2011.11.004.

4. Inglett GE, Chen D, Berhow M, Leeb S. Antioxidant activity of commercial buckwheat flours and their free and bound phenolic compositions. Food Chem. 2011;125:923-9. http://dx.doi.org/10.1016/j.foodchem.2010.09.076

5. Ferreres F, Souza C, Valentão P, Seabra RM, Pereira JA, Andrade PB. Tronchuda cabbage (Brassica oleracea L. var. costata DC) seeds: Phytochemical characterization and antioxidant potential. Food Chem. 2007;101:549-58. http://dx.doi.org/10.1016/j.foodchem.2006.02.013

6. Kusznierewicz B, Bartoszek A, Wolska L, Drzewiecki J, Gorinstein S, Namieśnik J. Partial characterization of white cabbages (Brassica oleracea var. capitata f. alba) from different regions by glucosinolates bioactive compounds total antioxidant activities and proteins. LWT-Food Sci Technol. 2008;41: $1-9$. http://dx.doi.org/10.1016/j.lwt.2007.02.007

7. Soengas P, Cartea ME, Francisco M, Sotelo T, Velasco P. New insights into antioxidant activity of Brassica crops. Food Chem. 2012;134:725-33. http://dx.doi.org/10.1016/j.foodchem.2012.02.169.

8. Vrchovská V, Sousa C, Valentão P, Ferreres F, Pereira JA, Seabra RM, Andrade PB. Antioxidative properties of tronchuda cabbage (Brassica oleracea L. var. costata DC) external leaves against DPPH, superoxide radical, hydroxyl radical and hypochlorous acid. Food Chem. 2006;98:416-42. http://dx.doi.org/10.1016/j.foodchem.2005.06.019
9. Hurtado FC, Gicquel M, Esnault MA. Evaluation of the antioxidant potential of cauliflower (Brassica oleracea) from a glucosinolate content perspective. Food Chem. 2012;132: 1003-9. http://dx.doi.org/10.1016/j.foodchem.2011.11.086

10. Zhou K, Yu L. Total phenolic contents and antioxidant properties of commonly consumed vegetables grown in Colorado. LWT-Food Sci Technol. 2006;39:1155-62. http://dx.doi.org/10.1016/j.lwt.2005.07.015

11. Ou B, Huang D, Hampsch-Woodill M, Flanagan JA, Deemer EK. Analysis of antioxidant activities of common vegetables employing oxygen radical absorbance capacity (ORAC) and ferric reducing antioxidant power (FRAP) assays: A comparative study. J Agric Food Chem. 2002;50:3122-8. http://dx.doi.org/10.1021/jf0116606

12. Jaiswal AK, Abu-Ghannam N, Gupta S. A comparative study on the polyphenolic content, antibacterial activity and antioxidant capacity of different solvent extracts of Brassica oleracea vegetables. Int J Food Sci Tech. 2012;47:223-31. http://dx.doi.org/10.1111/j.1365-2621.2011.02829.x

13. Blazevic I, Radonic A, Mastelic J, Zekic M, Skocibusic M, Maravic A. Glucosinolates glycosidically bound volatiles and antimicrobial activity of Aurinia sinuat (Brassicaceae). Food Chem. 2010;121:1020-8. http://dx.doi.org/10.1016/j.foodchem.2010.01.041

14. Chemat F, Huma Z, Khan MK. Applications of ultrasound in food technology: Processing, preservation and extraction. Ultrason Sonochem. 2011;18:813-35. http://dx.doi.org/10.1016/j.ultsonch.2010.11.023

15. Dubie J, Stancik A, Morra M, Nindo C. Antioxidant extraction from mustard (Brassica juncea) seed meal using highintensity ultrasound. J Food Sci. 2013;78:42-8. http://dx.doi.org/10.1111/1750-3841.12085.

16. Da Porto C, Porretto E, Decorti D. Comparison of ultrasound-assisted extraction with conventional extraction methods of oil and polyphenols from grape (Vitis vinifera L.) seeds. Ultrason Sonochem. 2013;20:1076-80.

http://dx.doi.org/10.1016/j.ultsonch.2012.12.002

17. Li Y, Fabiano-Tixier AS, Tomao V, Cravotto G, Chemat F. Green ultrasound-assisted extraction of carotenoids based on the bio-refinery concept using sunflower oil as an alternative solvent. Ultrason Sonochem. 2013;20:12-8. http://dx.doi.org/10.1016/j.ultsonch.2012.07.005

18. Pingret D, Fabiano-Tixier AS, Bourvellec CL, Renard CMGC, Chemat F. Lab and pilot-scale ultrasound-assisted water extraction of polyphenols from apple pomace. J Food Eng. 2012;111:73-81. http://dx.doi.org/10.1016/j.jfoodeng.2012.01.026

19. Achat S, Tomao V, Madanic K, Chibane M, Elmaataoui M, Dangles O, Chemat F. Direct enrichment of olive oil in oleuropein by ultrasound-assisted maceration at laboratory and pilot plant scale. Ultrason Sonochem. 2012;19:777-86. http://dx.doi.org/10.1016/j.ultsonch.2011.12.006.

20. Tanongkankit Y, Chiewchan N, Devahastin S. Evolution of anticarcinogenic substance in dietary fibre powder cabbage outer leaves during drying. Food Chem. 2011;127:67-73. http://dx.doi.org/10.1016/j.foodchem.2010.12.088

21. Haaland PD. Experimental design in biotechnology. New York, USA: Marcel Dekker; 1989.

22. Robbins RJ, Keck AS, Banuelos G, Finley JW. Cultivation conditions and selenium fertilization alter the phenolic profile, glucosinolate and sulforaphane content of broccoli. J Med Food. 2005;2:204-14. http://dx.doi.org/10.1089/jmf.2005.8.204

23. Leoni $\mathrm{O}$, Cinti S, Aliano N, Tittonel ED. A rapid chromatographic method for determining the glucosinolate content in crambe seed. Plant Breeding. 2003;122:517-20. http://dx.doi.org/10.1111/j.1439-0523.2003.00893.x 
24. Zhao H, Dong J, Lu J, Chen J, Li Y, Shan L, et al. Effects of extraction solvent mixtures and antioxidant activity evaluation and their extraction capacity and selectivity for free phenolic compounds in barley (Hordeum vulgare L.). J Agric Food Chem. 2006;54:7277-86. http://dx.doi.org/10.1021/jf061087w

25. Amado LL, Garcia ML, Ramos PB, Freitas RF, Zafalon B, Ferreira JLR, Yunes JS, Monserrat JM. A method to measure total antioxidant capacity against peroxyl radicals in aquatic organisms: Application to evaluate microcystins toxicity. Sci Total Environ. 2009;407:2115-23. http://dx.doi.org/10.1016/j.scitotenv.2008.11.038

26. Pingret D, Durand G, Fabiano-Tixier AS, Rockenbauer A, Ginies C, Chemat F. Degradation of edible oil during food processing by ultrasound: Electron paramagnetic resonance, physicochemical, and sensory appreciation. J Agric Food Chem. 2012;60:7761-8. http://dx.doi.org/10.1021/jf301286f

27. Pingret D, Fabiano-Tixiero AS, Chemat F. Degradation during application of ultrasound in food processing: A Review. Food Control. 2013;31:593-606. http://dx.doi.org/10.1016/j.foodcont.2012.11.039

28. Kitamura N, Ota Y, Haratake A, Ikemoto T, Tanno O, Horikoshi T. Effects of ethyl alpha-D-glucoside on skin barrier disruption. Skin Pharm Phys. 1997;10:153-9.

29. Liu X, Dong M, Chen X, Jiang M, Lv X, Yan G. Antioxidant activity and phenolics of an Xylaria sp. from Ginkgo biloba. Food Chem. 2007;105:548-54. http://dx.doi.org/10.1016/j.foodchem.2007.04.008

30. Fischer CL, Drake DR, Dawson DV, Blanchette DR, Brogden KA, Wertz PW. Antibacterial activity of sphingoid bases and fatty acids against Gram-positive and Gram-negative bacte- ria. Antimicrob Agents Chemother. 2012;56:1157-61. http://dx.doi.org/10.1128/AAC.05151-11.

31. Halliwell B, Gutteridge JMC. Free radicals in biology and medicine. 4th ed. New York, USA: Oxford University Press; 2007.

32. Kurilich AC, Jeffery EH, Juvik JA, Wallig MA, Klein BP. Antioxidant capacity of different broccoli (Brassica oleracea) genotypes using the oxygen radical absorbance capacity (ORAC) assay. J Agric Food Chem. 2002;50:5053-7. http://dx.doi.org/10.1021/jf0255351

33. Wu X, Gu L, Holden J, Haytowitz DB, Gebhardt SE, Beecher, Prior GRL. Development of a database for total antioxidant capacity in foods: A preliminary study. J Food Compos Anal. 2004;17:407-22. http://dx.doi.org/10.1016/j.jfca.2004.03.001

34. Podsedek A. Natural antioxidants and antioxidant capacity of Brassica vegetables: A review. LWT-Food Sci Technol. 2007;40:1-11. http://dx.doi.org/10.1016/j.lwt.2005.07.023

35. Parekh J, Chanda S. In vitro antimicrobial activity of Trapa natans L. fruit rind extracted in different solvents. Afr J Biotechnol. 2007;6:766-70.

36. Soares D, Lerin LA, Cansian RL, Oliveira JV, Mazutti MA. Inactivation of Listeria monocytogenes using superctitical carbon dioxide in a high-pressure variable-volume reactor. Food Control. 2013;31:514-8. http://dx.doi.org/10.1016/j.foodcont.2012.11.045

37. Ayaz FA, Hayırlıglu-Ayaz S, Alpay-Karaoglu S, Grúz J, Valentová K, Ulrichova J, Strnad M. Phenolic acid contents of kale (Brassica oleraceae L. var. acephala DC.) extracts and their antioxidant and antibacterial activities. Food Chem. 2008; 107:19-25.

http://dx.doi.org/10.1016/j.foodchem.2007.07.003 